\title{
Right Securement, Dressing, and Management
}

\author{
Steve Hill and Nancy L. Moureau
}

\begin{abstract}
This chapter considers the role of securement in CVAD care, providing an overview of the background and how knowledge and research has evolved in this area. The complications of inadequate securement such as infection, migration, pistoning, and medical adhesiverelated skin injury (MARSI) are examined to understand contributing factors that lead to their development. Practices that enhance optimal securement and mitigate risks are discussed as part of the clinician's role in the prevention of complications in our endeavor to reach our ultimate goal of achieving zero CVAD complications.
\end{abstract}

\section{Keywords}

Securement · Intravenous catheter · Central catheter - Stabilization · Dislodgement .

Catheter failure

S. Hill

The Christie NHS Foundation Trust, Manchester, UK

Precision Vascular and Surgical Services Ltd, Manchester, UK

e-mail: info@precisionvascular.co.uk; steve.hill@christie.nhs.uk

N. L. Moureau $(\bowtie)$

PICC Excellence, Inc., Hartwell, GA, USA

Menzies Health Institute, Alliance for Vascular Access Teaching and Research (AVATAR) Group, Griffith University, Brisbane, QLD, Australia e-mail: nancy@piccexcellence.com

\subsection{Introduction}

Following the insertion of a VAD, methods to secure the position and reduce movement of the catheter contribute to the longevity and functionality of the venous access device. Securement of a VAD plays a crucial role in the performance and the success of the device. The importance of securement is established by the rates of catheter failure, malposition, infection, and complications of dislodgment/pistoning. The impact of poor securement upon the patient can be significant, leading to delays or missed treatments and infection (Oliver and Jones 2014). Inadequate securement may also prolong hospital stays, and further interventions are needed or a replacement VAD is required. Accidental dislodgement incidence is estimated at 1.8-24\% of all VADs (Dugger et al. 1994; Moureau et al. 2002). Use of manufactured securement is intended to reduce the incidence of catheter failure due to dislodgement (Marsh et al. 2015). VHP provides a context for application of standardized securement processes that address issues of sutures, dressings, and forms of securement that combine both the use of cyanoacrylate and dressings. Securement is designed to minimize or eliminate dislodgment and related complications.

In the literature catheter failure rates prior to completion of therapy reflect an incidence of up to $69 \%$ (Marsh et al. 2015; Ullman et al. 2015a, b). Estimates reflect that $40-70 \%$ of peripheral 
intravenous catheters (PIVC) are due to dislodgment, occlusion, infiltration, or phlebitis, all complications which may be impacted by securement practices (Rickard and Marsh 2017). Movement of catheters in and out of the insertion site may cause inflammation, swelling, phlebitis, and infection that contribute to the need to remove and replace the catheter. Both peripheral and central catheters require adequate securement to reduce the risk of catheter failure and complications that contribute to increased morbidity and mortality during treatment.

For clinicians providing vascular access, there are few situations more frustrating and exasperating than after struggling painstakingly over a difficult placement and then to hear that the device has accidentally been pulled out. There are potential service implications too for vascular access teams or individual clinicians. Unnecessary repeated VAD insertions increase costs and reduce efficiency and may even increase waiting lists together with reducing capacity to respond to new patients referred who require a VAD.

As with the growth and divergence in vascular access devices, we have seen an increase in the variety of different methods of securing and dressing VADs. Once the VAD has been placed, our aim is to maintain cleanliness of the site by reducing microbial access and thereby reducing the cutaneous route of infection at the point where the device enters the skin. Protection and securement of a VAD must be effective to allow the VAD to achieve its intended dwell time and minimize complications.

Various studies have demonstrated the effectiveness of the differing types of securement with manufactured securement as the most highly recommended (Gorski et al. 2016; Ullman et al. $2015 \mathrm{a}, \mathrm{b})$. Types of catheter securement include tape and gauze, transparent film dressings that hold the catheter in place either independently or in conjunction with other forms of securement, more advanced dressings with borders and adherent strips, manufactured adhesive sutureless securement where the catheter is mounted and held in place through adhesive, anchoring or locking devices, tissue adhesives, more invasive subcutaneous securement, and sutures.

\subsection{Purpose of Securement}

The role of securement for devices is to limit movement, reduce transmission of external skin bacteria into the insertion site, and reduce the occurrence of accidental dislodgement often resulting in VAD failure. Effective forms of securement with a dressing cover help to protect the catheter and insertion site for up to 7 days as established in INS Standards (Gorski et al. 2016). The Standards also specify VADs should be stabilized and secured to prevent complications and unintentional loss of access. The Centers for Disease Control (CDC) recommends the use of sutureless securement to reduce the risk of infection for VADs (O'Grady et al. 2011). Commonly used forms of securement are transparent dressings that provide some degree of stabilization, allow visualization and assessment through the dressing, and prevent contamination from water or dirt while releasing moisture from the skin with varying levels of vapor permeability within the transparent film. Engineered stabilization devices are designed to reduce accidental dislodgement and other complications associated with movement and lack of securement.

\subsection{Types of Securement}

Devices used for securement of VADs include transparent dressings, tape and gauze, advanced dressings with borders and adherent strips, manufactured adhesive sutureless securement, anchoring or locking devices, tissue adhesives, subcutaneous securement, and sutures. Each of these forms of securement may be used in combination and can have slightly different applications. Patients with edema, anasarca, and drainage at the insertion site may require gauze and tape (Fig. 9.1) with dressing changes every $24-48 \mathrm{~h}$ in addition to an adhesive sutureless securement or subcutaneous securement device attached to the catheter. Sterile tape or reinforced strips can be used to secure the VAD to the skin and are most effective if used in a consistent and systematic manner by all staff. Manufacturers caution against the use of tape directly on catheters as it 


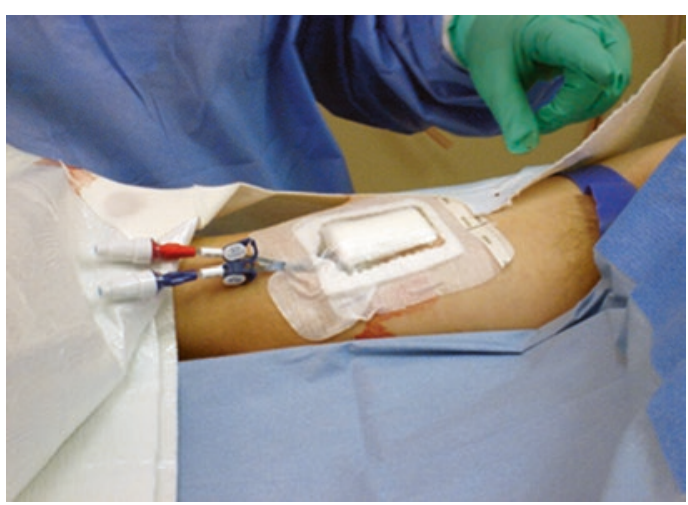

Fig. 9.1 Gauze dressing (used with permission of N. Moureau (PICC Excellence 2018))

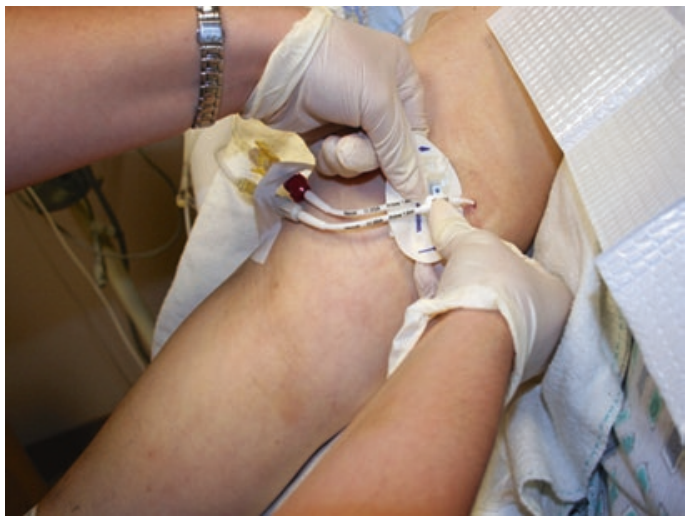

Fig. 9.2 Adhesive Securement Platform. Used with permission of Nancy Moureau, PICC Excellence

has been known to damage catheters during removal. Accidental dislodgement of catheters remains a problem when tape or reinforced strips are the only source of securement. Regardless of which product is used to secure the catheter, a securement device is changed with each dressing change or if it becomes soiled, bloody, or loose and is placed so that nothing interferes with insertion site assessment.

INS states a catheter stabilization device is the preferred alternative to tape or sutures (Gorski et al. 2016). There are several types of manufactured devices designed specifically for central venous catheters. Some are adhesive devices that allow the wings on the catheter hub to snap into a platform (Fig. 9.2), providing a firm base of stabilization. There are securement devices that have adhesive applied to skin and adhesive to hold the hub, and still others use a Velcro-strap material to cross over the hub to hold the lumens of the catheter and stabilize the device. Add-on plastic snap-on holders for the catheter create a place of securement around the catheter to lock onto a securement platform. Manufactured securement devices reduce dislodgement and are safer than sutures, tape, or strips. The manufactured devices are effective by maintaining a secure hold and preventing the catheter from pistoning in and out of the site. This reduction of movement of the catheter with adequate stabilization at the insertion site reduces movement of the catheter and may also reduce the introduction of microorganisms and catheter-related infection (Jeanes and Martinez-Garcia 2016).

\subsection{Gauze and Tape Securement}

In the early stages of VAD dressing development, Shivnan et al. (1991) compared the sterile gauze dressing with transparent adherent dressings for high-risk patients $(n=96)$ who were undergoing bone marrow transplants (Shivnan et al. 1991). In this study no significant difference was found in terms of infection, but transparent dressings were found to be less irritable than gauze and tape. Dressing types were evaluated for tunneled central venous catheters. Keeler et al. (2015) looked at the impact of three approaches and monitored rates of catheter-related infection and cost: no dressing, a gauze dressing, and a transparent dressing (Keeler et al. 2015). A total number of 432 patients were included in a single site comparison; no difference in infection rates, number of organisms, or days until the onset of an infection was noted between the groups. Gauze was found to have the highest cost of the three methods.

\subsection{Transparent Dressings}

Transparent dressings, as a type of securement, either alone or in conjunction with other forms of securement, include flat films or those with cloth borders. Bordered dressings may promote improved adherence of the edges with less lifting 
and reduce catheter dislodgement. According to INS, transparent dressings should not be relied upon to act as the single source of securement indicating the lack of supportive evidence (Gorski et al. 2016). Results of the study by Rickard et al. (2018) demonstrated similar dislodgement outcomes (7-10\%) for transparent dressings, bordered transparent, adhesive sutureless securement, and transparent and tissue adhesive with transparent dressing (Rickard et al. 2018). While the tissue adhesive and transparent dressing had the lowest dislodgement (7\%), the results were not statistically significant. This study, with single digit dislodgement rates reflected lower than average negative outcomes suggestive that initial securement by expert trained nurses (average of $87.7 \%$ of insertions) reduced complications. These results also emphasize the value of using a transparent dressing in combination with other forms of securement to reduce all complications. Dawn et al. (2010) undertook a prospective randomized study comparing adhesive sutureless securement with a transparent dressing with 302 subjects and found that the transparent dressing was non-inferior in respect of overall securementrelated complications (Dawn et al. 2010).

Peripheral catheters are the most common form of VAD and have the highest failure rate, up to $69 \%$, partially due to inadequate securement resulting in dislodgement (Rickard et al. 2010, 2012; Smith 2006). Evidence supports the use of two options for catheter stabilization of PIVCs

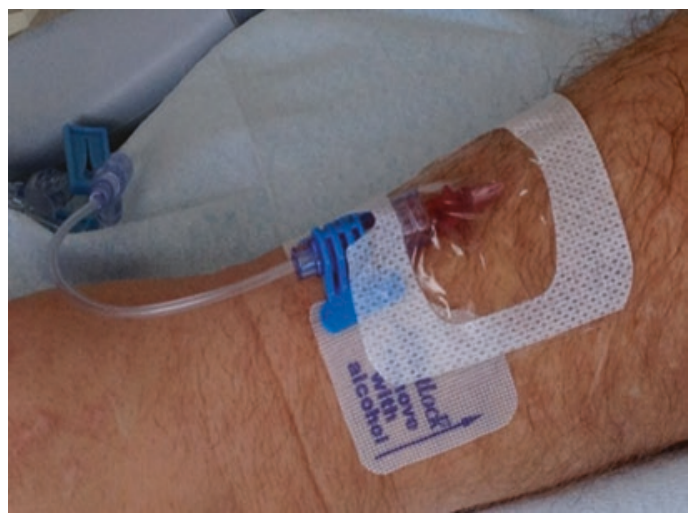

Fig. 9.3 Adhesive securement with PIVC dressing (used with permission of N. Moureau, PICC Excellence)
(Fig. 9.3), one for the hub and one as a dressing (Bausone-Gazda et al. 2010; Gorski et al. 2016; Jackson 2012).

\subsection{Adhesive Securement Platforms}

Traditionally the mechanism for securing some catheters for non-tunneled CVC and PICCs has been to suture them in place. Yamamoto et al. (2002) looked at two methods of securing PICCs, traditional suturing and adhesive sutureless securement looking at rates of dislodgement, occlusion, leakage, infection, and thrombosis (Yamamoto et al. 2002). The results demonstrated the adhesive sutureless securement complications were lower than the sutures group (42 vs. 61), though the difference did not reach statistical significance. There was, however, a significantly lower rate of catheter-related bloodstream infections in the adhesive sutureless securement group (2 vs. 10). The study also identified one needlestick injury which occurred during suturing. Adhesive sutureless securement is used with PIVC, midline, PICCs, and some chest, neck, and femoral CVADs (Fig. 9.3). Used in conjunction with a transparent dressing, this device is changed every 7 days or when the dressing is changed.

\subsection{Tissue Adhesive Securement}

For many years surgical glue has been used successfully in healthcare for a variety of applications, from traumatic lacerations to trocar port incisions (Regalado and Funaki 2008). In more recent times, medical grade surgical glue has attracted the attention from clinicians within the specialty of vascular access. Tissue adhesives or glue are now used with VADs with one drop on the insertion site and an optional drop under the hub of the catheter to provide stabilization and also have evidence to suggest a level of microbial protection (Pittiruti and Scoppettuolo 2017; Rickard et al. 2018; Simonova et al. 2012). Scoppettuolo et al. (2015) found that cyanoacrylate glue can be used as an alternative to suturing and helps to reduce 
site bleeding for VADs (Scoppettuolo et al. 2015). The authors suggest a $40 \%$ reduction in PICC related bleeding at the insertion site with $0 \%$ bleeding observed at $1 \mathrm{~h}$ and at $24 \mathrm{~h}$ in 45 patients. In a study at the same hospital, using cyanoacrylate glue on 348 PICCs (pediatric and adult) with 165 non-tunneled CVADs including high-risk coagulopathic patients, the study showed that the glue was $100 \%$ effective at preventing post-insertion bleeding at the exit site (Pittiruti et al. 2016). In PICCs glue was effective in preventing extraluminal bacterial contamination of the catheter (Pittiruti et al. 2016). Furthermore, the authors used an insertion bundle, which included glue in pediatric CVADs which resulted in a tenfold decrease in infection. Other advantages include increasing the speed of skin closure, for instance, when closing the wounds for implanted ports versus tradition time-consuming suture closure. The ability to close the port sites more quickly may reduce the risk the site is exposed to infection and reduce the risk of needlestick injury (Regalado and Funaki 2008). As with any adhesive, MARSI or skin irritation may occur making it prudent for the clinician to perform a skin test prior to use of any of the tissue adhesive formulations. Tissue adhesives are typically used in conjunction with a transparent dressing cover providing added securement of the catheter even if the dressing becomes non-adherent.

\subsection{Subcutaneous Securement}

Another type of engineered securement is the subcutaneous snap-on stabilization device with tungsten flanges that anchor the device around the catheter and in the subcutaneous tissue of the patient (Egan et al. 2013). This type of securement has been successful with CVADs resulting in favorable clinician and patient satisfaction (Bugden et al. 2016; Gorski et al. 2016; Jeanes and Martinez-Garcia 2016; Zerla et al. 2017). Subcutaneous securement applied to a catheter is left in place for the entire life of the catheter without replacement, unless complication or device dislodgement occurs, providing an excellent option for securement similar to suturing without the added concerns of puncture site infection.

\subsection{Sutures}

Sutures are often used for internal jugular or subclavian acute care catheters and designed for short-term. The process of inserting sutures as a form of securement requires multiple punctures through the skin creating an added risk of secondary local infection for the patient (Frey and Schears 2006). INS recommends avoidance of sutures or tape noting they are not as effective as securement devices and that sutures are associated with needlestick injuries, biofilm growth, and an increased risk of infection (Gorski et al. 2016). Research has shown manufactured devices such as adhesive securement to be equal to or better than sutures for stabilizing catheters. Rickard and colleagues (2016) performed a four-way randomized controlled trial looking at CVAD securement for 221 cardiac surgical patients (Rickard et al. 2016). The study looked at dressings/ securement combinations:

- Suture + bordered polyurethane (BPU), the control $=2(4 \%)$.

- Suture + gauze absorbent dressing $=1(2 \%)$.

- Adhesive sutureless securement + simple polyurethane dressing $(\mathrm{SPU})=4(7 \%)$.

- Tissue adhesive + SPD $=4(17 \%)-$ stopped mid-trial.

- Suture + tissue adhesive + SPU $=0(0 \%)$.

After CVAD dislodgement in the tissue adhesive + SPU arm, the researchers decided to cease randomization to this arm of the study and created a fifth arm for the remaining 30 patients that included suture + tissue adhesive + SPU. The results demonstrated combination approach to securement, and dressing had the best outcomes for those with sutures and dressing or adhesive securement and dressing.

The authors concluded that tissue adhesive and SPU were ineffective for CVAD securement in challenging post-cardiac patients, suture + tissue adhesive + SPU appeared promising with zero CVAD failure, and further research was required. Infection rates were not measured. The study illustrates the limitations a number of approaches to secure VADs and that perhaps the 
solutions for successful securement/dressings outcomes are as a result of using a number of methods, which when combined, provide more favorable outcomes.

\subsection{Add-On Securement Devices}

Safety release valves, as disposable tubing stopcheck valves, can contribute to the reduction of catheter failure from dislodgement and provide increased patient safety by blocking blood or fluid flow whenever disconnection of the catheter occurs. Disconnection of tubing and dislodgement of catheters often occurs with normal patient activity. Add-on devices in the form of quick release valves may reduce catheter failure and provide a novel option for securement.

\subsection{Impact of Inadequate Securement}

Regardless of the type of vascular access device, a PIVC, midline, PICC, and non-tunneled or tunneled CVAD, dislodgement and premature removal can occur. Dislodgement or accidental removal can disrupt patient therapy, perhaps even contributing to exacerbation of medical conditions through treatment delays, this can create anxiety for patients who may need a replacement of a VAD and increase healthcare cost. Rickard et al. (2015) estimate that up to $69 \%$ of PIVC fail prior to treatment completion (Rickard et al. 2015). The most common reason for PIVC failure is due to infiltration or dislodgement (Royer 2003), and it is estimated that $10 \%$ simply fall out (Rickard et al. 2015). Ventura et al. (2016) quote dislodgement rates from 10.2 per 1000 cases in pretrial data and 0 per 1000 when trialing different methods of securement for midline catheters. Hughes et al. (2014) identified a PICC post-insertion misplacement rate was approximately $4.5 \%$, based on 460 PICC insertions and an actual replacement rate of 21 PICCs using wound closure strips, adhesive sutureless securement device, and a semipermeable dressing (Hughes 2014). Lorente et al. (2004) reviewed accidental

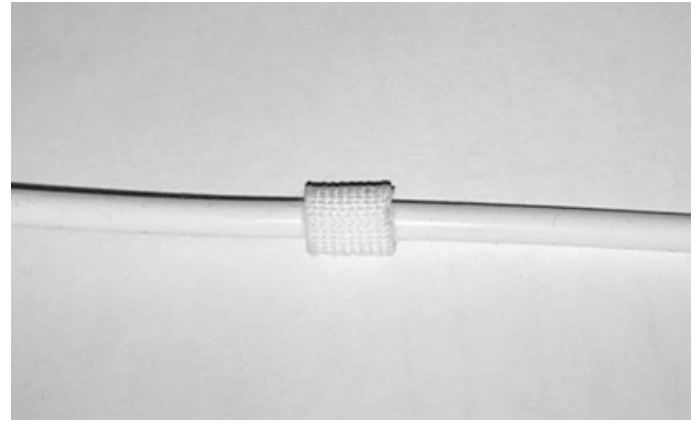

Fig. 9.4 Tunneled Dacron cuffed catheter (used with permission of S. Hill, Precision Vascular)

catheter removal including the rate of accidental catheter removal of non-tunneled CVADs, 2.02/100 catheter-days (Lorente et al. 2004). In a retrospective study looking at tunneled CVAD and PICC complications, Wong et al. (2015) identified a dislodgement/migration rate of 3 out of 29 PICCs $(10.3 \%)$ versus the tunneled CVAD group of 4 out of 161 patients $(2.4 \%)$ (Wong et al. 2015).

Even cuffed tunneled CVADs, where the patients' tissues engraft onto the cuff, are not completely resistant to dislodgement. The cuff, positioned approximately $1 \mathrm{~cm}$ within the insertion tract, becomes embedded into the tissues within weeks following insertion (Fig. 9.4). Until the cuff is fully secured, surgical glue or sutures and dressings may be used to aid securement and prevent infection. During those early weeks, before tissues have grafted onto the cuff, the catheter is as vulnerable to dislodgement as other non-cuffed devices. The catheter may be positioned under a dressing in a curved configuration that resists accidental pull of the catheter; the tension may be displaced by the curled catheter, thereby protecting the catheter cuff external migration. However, if the cuff is pulled out of the tissues and exposed (Simcock 2008), the catheter is no longer secured and resulting in distal CVAD tip migration.

Pistoning is the mechanical motion of the catheter in and out of the skin, which can lead to irritation of the intima of the vessel and over time potentially contribute to thrombotic changes (Macklin and Blackburn 2015). Macklin and 
Blackburn (2015) elaborate particularly in respect to PICCs that "pistons" in the vein increase the possibility of phlebitis or infection. Rickard et al. (2018) explains the micro-motion is a phenomenon seen in PIVCs causing inflammation presenting with pain, swelling, occlusion, and infiltration and may increase infection (Rickard et al. 2018).

Ullman et al. (2015a, b) describe earlier methods to secure CVADs was to use simple tape or gauze. In the 1980s and 1990s, transparent dressings gained more prominence. When simple tape and gauze are used as a form of securement, the clinician's ability to inspect the site may be limited and visualization of the VAD site impaired until the dressing is changed. Next generation dressings that were transparent facilitated easier inspection of the site. Frasca et al. (2010) explains: "Because occlusive dressings trap moisture on the skin and provide an ideal environment for quick local microflora growth, these dressings for insertion sites must be permeable to water vapor" (Frasca et al. 2010). Webster et al. (2011) confirm this point in their Cochrane review; initial concerns were present that surface humidity may lead to infection. Dressings with vapor-permeable film are now used allowing moisture to pass through the dressing away from the skin while maintaining a water and contaminant barrier.

Dressing and securement devices are not free from adverse effects. Cutting (2008) suggests the repeated application and removal of adhesive tapes and dressings from the same site can cause damage to the skin by "skin stripping," namely, the removal of superficial stratum corneum, which can cause inflammation, skin reactions, edema, and soreness. Repeated dressing change within a short period of time may lead to changes in skin integrity, potentially causing damage, pain, increased costs, and incidence of skin colonization (Webster et al. 2011). Understanding and managing the effects of dressings/securement devices is multifaceted and can involve a multitude of single or combination of variables.

Ensuring adequate securement for VAD is a routine occurrence in many clinicians' everyday practice, but there are sometimes some unwanted side effects. Applying another layer upon the skin surface by using a dressing or securement occasionally leads to problematic skin reactions. The damage from reapplication and removal may not always be visible as superficial skin layers are damaged during this process. Skin injury is increased when the adhesive attachment to the skin is stronger than the cutaneous layers of the skin and their attachment to cells (McNichol et al. 2013).

A consensus summit was held of key opinion leaders in December 2012, specialists in dermatology, geriatrics, orthopedics, plastic surgery, and researchers in the panel providing guidance on the subject including assessment, prevention, and treatment of MARSI (McNichol et al. 2013). The specialist team defined MARSI as: "A medical adhesive-related skin injury is an occurrence in which erythema and/or other manifestation of cutaneous abnormality (including, but not limited to, vesicle, bulla, erosion, or tear) persists $30 \mathrm{~min}$ utes or more after removal of the adhesive."

Multiple factors that increase the likelihood of damage to the patient's skin when dressings and adhesive sutureless securement devices are applied to the skin are intrinsic or extrinsic (Fig. 9.5). The damage from reapplication and removal may not always be visible as superficial skin layers are damaged during this process. Intrinsic factors are patient-specific factors that influence the individual integrity of the skin such as topical infections, including eczema, dermatitis, or, for example, if the patient has been taking long-term steroidal therapy. Or there may be transient factors where the patient at particular point in time may be malnourished or dehydrated making their skin more fragile than in normal daily life. If the patient is receiving anticancer therapy and is immunosuppressed or has radiation treatment, these factors can lead to the fragility of the skin and its susceptibility to infections (McNichol et al. 2013). Increasing age is unfortunately not an ally to skin integrity, and an inverse relationship exists, as age increases, skin integrity eventually decreases. Mechanical changes also occur with age including reduced blood flow through reduced size of the vasculature, hydration is reduced, and inflammatory processes are enhanced (Cutting 2008). Aging 


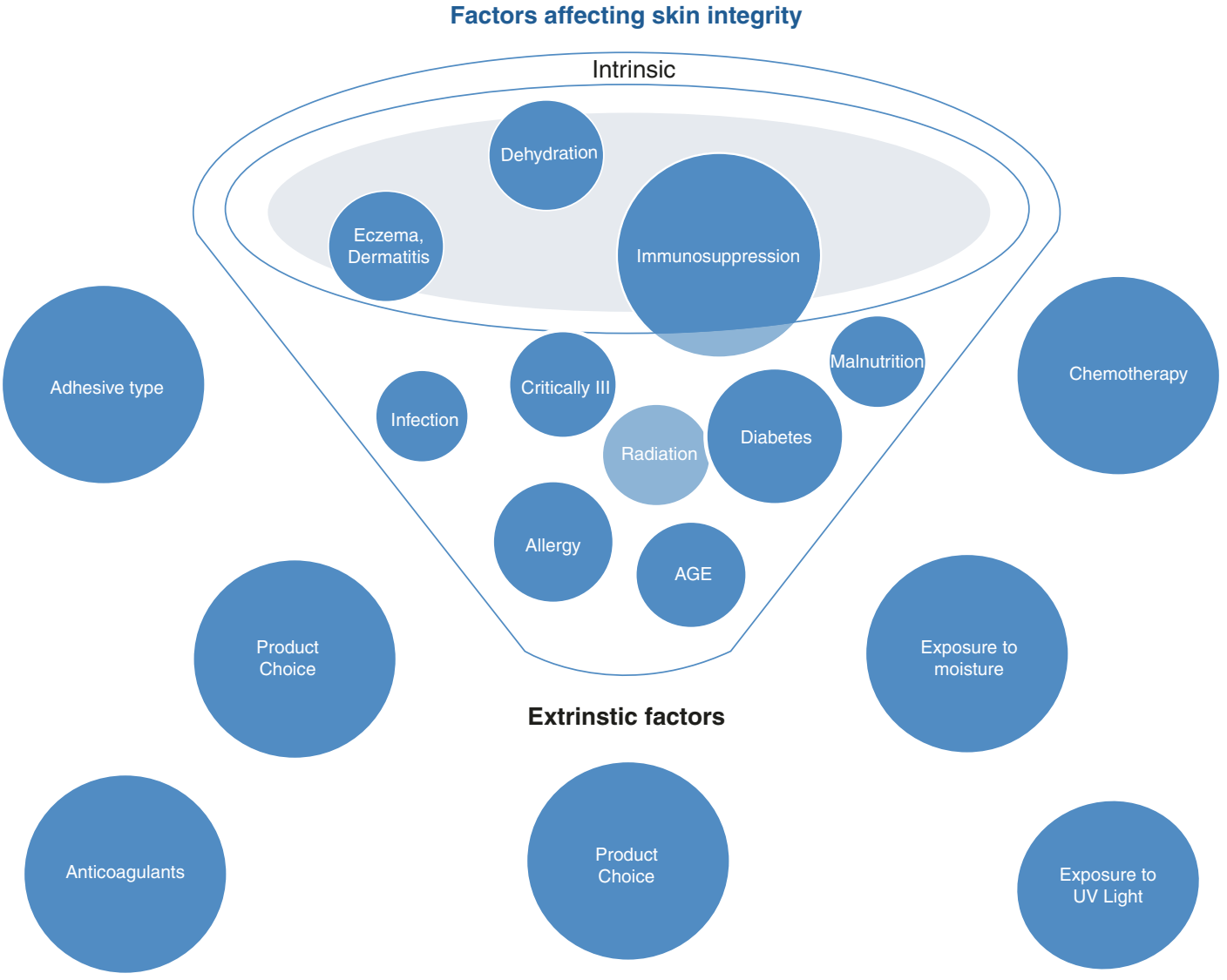

Fig. 9.5 Extrinsic factors for the skin and dressing securement. Modified from McNichol et al. (2013), understanding and guarding against medical adhesive-related skin injuries (MARSI) (Courtesy of 3M 2016)

affects the skin by loss of dermal matrix and subcutaneous tissue, reduced cohesion between dermal and epidermal layers and loss of elasticity (Thayer 2012). Enhanced inflammatory responses, reduction in cutaneous vessel size, and potentially neoplasms are increased the older we become; hydration and resiliency of skin are also intimately linked with age (Cutting 2008).

Extrinsic variables influence health of the skin, such as the prolonged exposure to moisture leading to maceration (Fig. 9.6) or application and removal technique (McNichol et al. 2013). The implications of using adhesive tapes and dressings on the skin can result in the superficial stratum corneum being removed with them, which Cutting (2008) describes as skin stripping. Medical adhesive can be pressure sensitive; increased application pressure increases the contact surface area that the dressing and adhesive has with the skin and may impact upon the super-

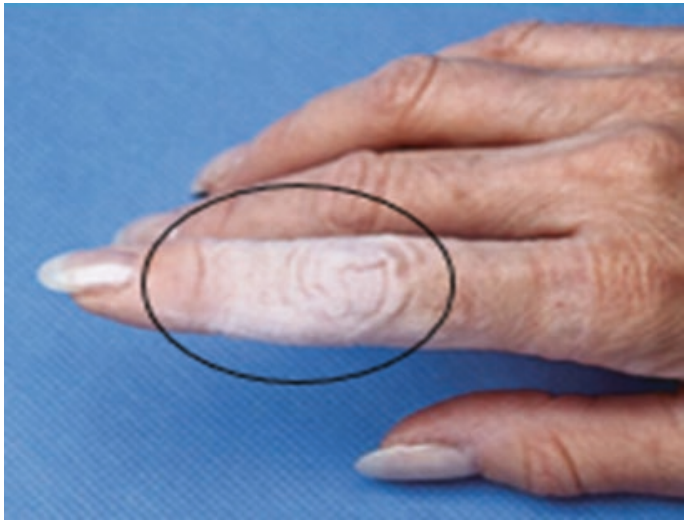

Fig. 9.6 Maceration from a saturated dressing (courtesy of $3 \mathrm{M}$ )

ficial layers of skin when removal occurs. Thereby, increased pressure applied to the dressing increases the bond with the skin and may increase the damage to the skin upon removal. 
Skin assessment is an established part of healthcare, to check surgical site healing, avoiding dermatological conditions and by taking preventative measures such as the assessment of pressure related skin and tissue damage (Yue et al. 2014). Similarly, the assessment and monitoring of VAD sites is an integral part of many healthcare providers. Vascular access and infection prevention guidelines around the globe advocate the close monitoring of the vulnerable areas of the body where vascular devices break the protective barrier of the skin (Gorski et al. 2016; Loveday et al. 2014; Pittiruti et al. 2009; RCN 2016; RNAO 2008). The ongoing assessment and monitoring of the VAD insertion site is essential to detect any subtle changes that may indicate that the area has deteriorating skin integrity and could lead to infection or skin reactions. The VHP daily assessment tool (Fig. 9.7) advocates that the VAD site should be assessed regularly to ensure the device has not dislodged or is occluded and also to consider if the device is still appropriate and necessary. In some instances, changes in medical conditions or treatment therapy will indicate that an alternative VAD is appropriate (Hallam et al. 2016). VHP also promotes observation of the site for signs of leakage or infection and to assess this by using vascular access site scoring system, such as the VIP scoring system (Gorski et al. 2016; Jackson 1998). However, if we are to reduce and avoid incidence of MARSI, maceration, dermatitis, and other skin reactions, our assessment of VAD sites needs to be broader reaching in order to provide early detection of complications. Clinical practice should not solely focus upon signs of phlebitis and infection. We need to shift from practice being responsive and reactionary to problems related to dressings, securement, and VADs to a more proactive approach by employing a preventative approach. The aim should be to adopt a preventative healthcare culture with a holistic, comprehensive approach identifying patientspecific features and environmental and productrelated factors that increase risk for patients while continuing to be vigilant monitoring, treating, and providing ongoing evaluation of VAD sight problems that may occur.

The success of a securement device can be judged on its durability and if it remains in place and supports the VAD and contributes to the device achieving its intended dwell time. Attention should also be given to how comfortable it is for the patient, how it affects the skin when applied and removed, and how userfriendly it is for the clinician to apply and remove (Ventura et al. 2016). A dressing should also provide protection against pathogens, allow visualization of the VAD site, be breathable, be comfortable for the patient, and be easy for the user to apply and remove.

Along with these desirable features we would choose for dressing and securement, selection should also be based upon its ability to reduce unwanted iatrogenic effects such as infection, skin irritation, and if the device achieves its intended dwell time.

Comprehensive patient assessment helps give the clinician insight into the individual vulnerabilities the patient may have and in turn inform the choice of dressing. Optimal dressing choice with consideration to the individual needs of the patient may increase the success of the dressing and/or securement and in turn minimize complications related the VAD being secured. Selection should be based upon the intended purpose, anatomical location, breathability, and flexibility, such as higher-risk areas like IJ (internal jugular) placement.

Consider high IJ placement of CVADs (Figs. 9.8 and 9.9), which is still common practice in many critical care settings. The weight of multiple IV infusions upon the catheter can pull and lift the dressing, releasing its contact from the skin and provide a route for pathogenic organisms to the CVAD site. There are alternative solutions to this problem, one is to avoid the high placement in the first instance by using a cannulation point at the lower aspect of the patient's neck or brachiocephalic access, allowing placement of the catheter upon the patient's clavicular/ upper pectoral area (discussed in Part III). Catheters in high IJ positions can lead to the problem of catheter drag, but there are alternate solutions. Not only is the appropriate dressing/ securement important but also the position of the patient, infusion pumps, tubing and that the tubing can move freely with the patient if conscious. 


\section{Daily Vessel Health Assessment Tool}

Patient Medical ID \#:

Date:

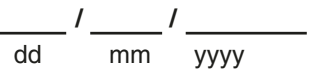

Nursing Information

1. How comfortable is the patient with their vascular access device? (ask the patient)
$\square 5$ - Extremely comfortable
$\square 2$ - Somewhat uncomfortable
$\square 4$ - Somewhat comfortable
$\square 1$ - Very uncomfortable
ㅁ 3 - Comfortable
$\square$ N/A due to confusion /sedation or other

If \#2 or \#1 checked, please explain the reason for discomfort:

2. What is the current device(s)? (check all that apply)

\begin{tabular}{lllllll} 
Type: $\quad \square$ PIV & $\square$ Midline & $\square$ PICC & $\square$ CVC & Port & \multicolumn{1}{c}{ Pialysis } & \\
Number of Lumens & $\square 1$ & $\square 2$ & $\square 3$ & Which Device? & $\square$ PICC & $\square$ CVC \\
No. of Lumens in Use & $\square 1$ & $\square 2$ & $\square 3$ & Which Device? & $\square$ PICC & $\square$ CVC
\end{tabular}

3. What complications, if any occurred within the last 24 hours (PIV)? (check all that apply)
$\square$ Infiltration
$\square$ Multiple restarts in $24 \mathrm{hrs}$
$\square$ Phlebitis/thrombophlebitis
$\square$ Infection

$\square$ Other

4. Did any complications occur within the last 24 hours with Central Venous Access Device(s)? $\quad \square$ Yes $\quad \square$ No
If Yes, check all that apply. Which Device? $\square$ PIV
$\square$ Infection
$\square$ Phlebitis
$\square$ Midline
$\square$ PICC
$\square \mathrm{CVC}$
$\square$ Port $\square$ Dialysis
$\square$ Partial Withdrawal Occlusion $\square$ Thrombosis
$\square$ Occlusion
$\square$ Occlusio

5. Is this patient having any difficulty with eating and drinking?

6 . Are there IV medications ordered other than PRN?

7. Is the VAD absolutely neccessary for blood draws with this patient?

$\begin{array}{ll}\square \text { Yes } & \square \text { No } \\ \square \text { Yes } & \square \text { No } \\ \square \text { Yes } & \square \text { No }\end{array}$

Nursing Recommendation:

Print Name:

RN/NP/PA/IVRN (circle)

8. Referring to the VHP Right Line Tool is the Venous access device(s) most appropriate for the current treatment plan?

If No, What device would apply based on Right Line Tool Selection?

$\square$ Yes $\square$ No

9. Is there any reason to maintain the current device(s)?

If Yes, (other than the above reason) Why?

RECOMMENDATIONS:

$\square$ Discontinue device(s) $\square$ Maintain device(s)

$\square$ Consider new device(s) from VHP Assessment Trifold

Recommended new device(s)

Physician/Pharmacist Info:

Print Name: MD/PharmD (circle)

(Information can be obtained by interview or by phone)

10. would switch to all oral medications be contraindicated at this time for this patient?

11. Is there an active blood stream infection?

12. Will access be required once the patient is released?

13. What is the current discharge plan?

14. Is the current IV device still necessary for this treatment plan and this patient? If Yes, please explain:

$\square$ IV needed additional days Number of additional day(s)

$\square$ Critical condition

$\square$ Other

\section{Action Plan:}

See nursing recommendation(s). If two or more NO answers, consider discontinuation of all IV devices to reduce risk to patient.

FINALACTION:

$\square$ Discontinue device(s)

Maintain device(s)

$\begin{array}{lr}\square \text { Yes } & \square \text { No } \\ \square \text { Yes } & \square \text { No } \\ \square \text { Yes } & \square \text { No } \\ \text { \# of days left } \\ \square \text { Yes }\end{array}$

For internal review:

ㅁ $25 \% \quad \square 50 \% \quad \square 75 \% \quad \square 100 \%$

Fig. 9.7 Daily assessment tool (used with permission of Teleflex)

As discussed, pathological/intrinsic factors and extrinsic factors (see Fig. 9.10) impact upon skin health can help mitigate the symptoms of MARSI, if we apply best practices and select the most appropriate dressings for the patient. INS guidelines suggest we should:
"Assess skin when the device is changed; anticipate potential risk for skin injury due to age, joint movement, and presence of edema" (Gorski et al. 2016) and that we should apply barrier solutions to skin exposed to the adhesive dressing to reduce the risk of MARSI (Gorski et al. 2016). 


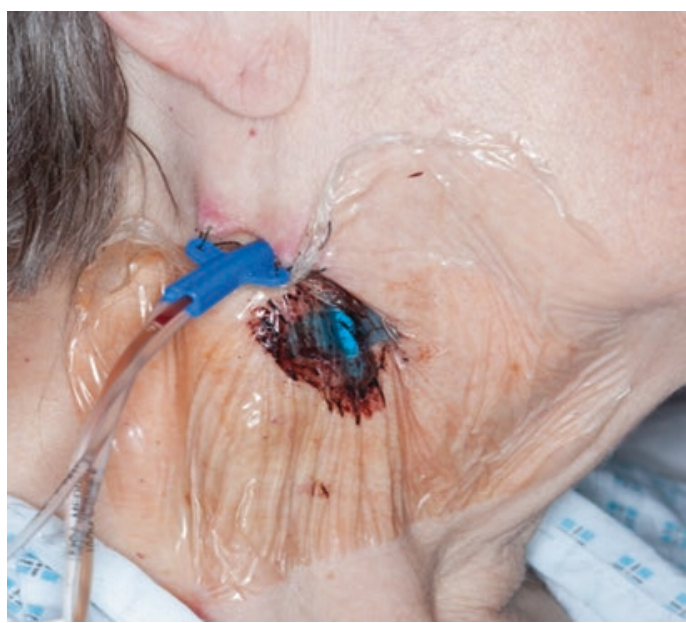

Fig. 9.8 Suture site with loose dressing and signs of infection (used with permission S. Hill, The Association for Safe Aseptic Practice (ASAP))

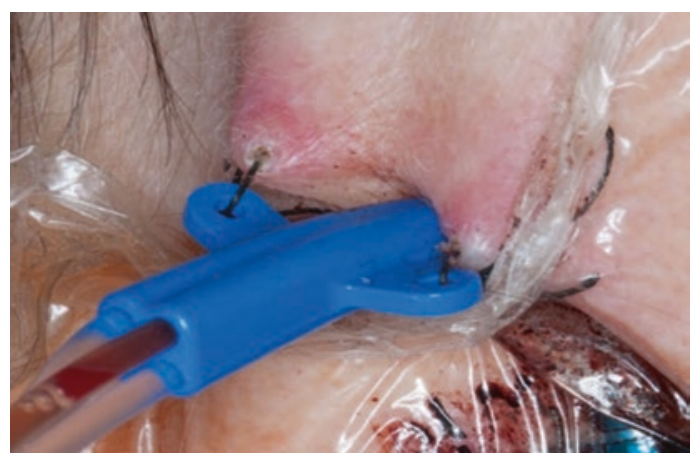

Fig. 9.9 Jugular Non-tunneled CVAD (used with permission S. Hill, The Association for Safe Aseptic Practice (ASAP))

Simply giving sufficient time for the skin to dry fully following cleaning prevents trapping moisture under the skin which can lead to dermatitis or maceration. Care should be taken not to overstretch the dressing and cause undue tension on the skin. Similarly, removal technique can result in unnecessary damage to the skin if done incorrectly. The skin must be supported as the dressing is being pulled back and continue to support the skin close to where it is being removed. Remove the dressing low and slow over itself in the direction of the hair growth and use medical adhesive remover if needed (McNichol et al. 2013) for vulnerable tissue and skin.

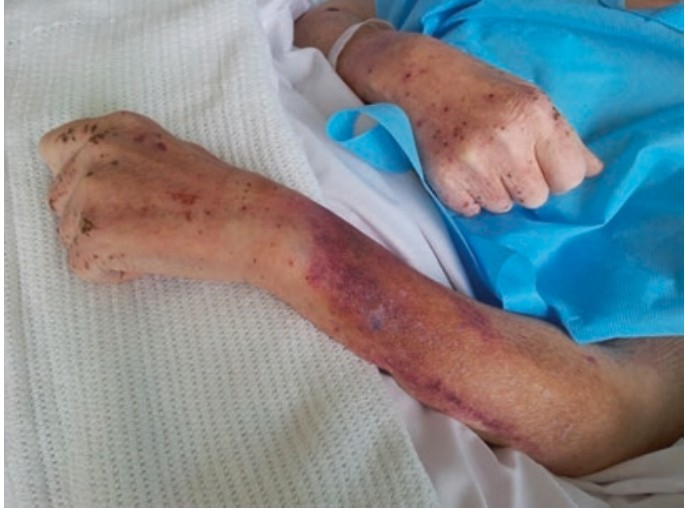

Fig. 9.10 Patient with aged skin and injury (used with permission S. Hill, The Association for Safe Aseptic Practice (ASAP))

When applying the dressing, ensure that undue pressure is not applied bearing in mind that many adhesives are pressure sensitive and increased adhesion occurs with increased pressure. Especially for the patient with a history of steroid medications and those with visibly thin, fragile skin special care should be given to application and removal. The pressure applied increases the skin surface area contact with the adhesive, and so greater pressure applied will increase the tension needed to remove the dressing and the stripping effect upon the patients' skin (McNichol et al. 2013). Optimal pressure must be applied to the individual needs of the patient, increased pressure may be appropriate for higher-risk areas such as IJ placements if skin integrity is sufficiently healthy, but a more sensitive application is required with patients with greater skin vulnerabilities. We cannot expect that we can exclude all risks of MARSI by solely focusing upon dressing choice, holistic assessment of the patient, and addressing risk factors by providing adequate nutrition, hydration, and balanced nutritional needs will all help to optimize patient outcomes.

\subsection{Conclusion}

Securement of VADs is a vital component to ensure patient safety through maximizing device dwell time and function while minimizing com- 
plications. Selecting the most appropriate form of securement with dressing type depends upon the device, the patient's previous experience with adhesives, the evidence supporting types of devices, and the knowledge of the clinician in correctly applying the selected securement device(s). Education is necessary in all phases of VAD management including the assessment and provision of dressings and securement and is essential to achieving the best outcomes in the VHP patient process.

\section{Case Study}

A young female patient in her 20s who was receiving chemotherapy for lymphoma. She was receiving this chemotherapy via a PICC secured with a standard polyurethane dressing with sutureless securement device plus sterile tapes. Some weeks into her treatment, she developed an allergy to the dressing. We discussed about dressing change frequency and general care and maintenance, to see if we could pick up anything from how it was being cared for that may have been contributing to the problems she was experiencing. However, she was being cared for by a very experienced team of hematology nurses who were seeing the patient once or twice a week, and the care being given was in line with hospital policy. We replaced the dressing with alternative polyurethane dressing and applied a sterile barrier film as to protect the skin from the adhesive and the dressing. We gave the patient the necessary information about looking out for increasing symptoms and to contact us at the earliest opportunity if there were any problems. The patient presented the next day with similar issues that she had experienced with the previous dressing and the medical/ nursing team decided upon a pragmatic approach to identify the suitability of dressing for the patient and used small amounts of dressing from each of the available transparent, semipermeable dressings used in the hospital and placed them on the patient's forearm. The patient was monitored for an hour to see if there was any skin reaction and if the was one that did not cause a skin reaction. To the surprise of the team, all four came back having caused an allergic reaction to the skin. The team then decided to use sterile tape and gauze, supported with a tubular elasticated support; the patient had the PICC in for a further 2 months without infection or other complications and the reactions from the adhesive dressings resolved.

\section{Case Study}

A 75-year-old female was admitted to hospital for pneumonia and required an ultrasound-guided peripheral catheter (UGPIV) insertion due to difficult venous access and multiple failed attempts at PIVC placement. Following successful aseptic placement of the UGPIV, the clinician wanted to take special care to secure the catheter to prevent accidental dislodgement. The PIVC hub was secured with a small drop of tissue adhesive at the insertion site and another under the hub. A bordered transparent dressing applied on top of the insertion area with pressure applied to all edges to ensure proper adherence. Treatment with antibiotics continued for 5 days with no PIVC complications. Prior to discharge from hospital, the PIVC was inspected and removed. No skin irritation or other complications were noted.

\section{Summary of Key Points}

1. Securement takes the form of a transparent dressing, tape, and gauze, advanced dressings with borders and adherent strips, manufactured adhesive securement platforms, anchoring or 
locking devices, tissue adhesives, subcutaneous securement, and sutures.

2. Securement of VADs is a component necessary to promote complication free survival of a VAD.

3. Manufactured securement aids in reducing movement of the catheter stabilizing position and avoiding complications such as phlebitis, infection and dislodgement.

\section{References}

Bausone-Gazda D, Lefaiver C, Walters S. A randomized controlled trial to compare the complications of 2 peripheral intravenous catheter-stabilization systems. J Infus Nurs. 2010;33:371-84.

Bugden S, Shean K, Scott M, Mihala G, Clark S, Johnstone C, Fraser JF, Rickard CM. Skin glue reduces the failure rate of emergency department-inserted peripheral intravenous catheters: a randomized controlled trial. Ann Emerg Med. 2016;68:196-201.

Cutting K. Impact of adhesive surgical tape and wound dressings on the skin, with reference to skin stripping. J Wound Care. 2008;17:157-62.

Dugger B, Macklin D, Rand B. Veni-gard (R) versus standard dressings on hemodynamic catheter sites. Dimens Crit Care Nurs. 1994;13:84-9.

Egan G, Siskin G, Weinmann R IV, Galloway M. A prospective postmarket study to evaluate the safety and efficacy of a new peripherally inserted central catheter stabilization system. J Infus Nurs. 2013;36:181-8.

Frasca D, Dahyot-Fizelier C, Mimoz O. Prevention of central venous catheter-related infection in the intensive care unit. Crit Care. 2010;14:212.

Frey A, Schears G. Why are we stuck on tape and suture? J Infus Nurs. 2006;29:34-8.

Gorski L, Hadaway L, Hagle M, Mcgoldrick M, Orr M, Doellman D. Infusion therapy: standards of practice (supplement 1). J Infus Nurs. 2016;39:S1-S159.

Hallam C, Weston V, Denton A, Hill S, Bodenham A, Dunn H, Jackson T. Development of the UK Vessel Health and Preservation (VHP) framework: a multi-organisational collaborative. J Infect Prev. 2016;17:65-72.

Hughes ME. Reducing PICC migrations and improving patient outcomes. Br J Nurs. 2014;23:S12-8.

Jackson A. Infection control-a battle in vein: infusion phlebitis. Nurs Times. 1998;94(68):71.

Jackson A. Retrospective comparative audit of two peripheral IV securement dressings. Br J Nurs. 2012;21:10-5.

Jeanes A, Martinez-Garcia G. Intravenous securement devices: an overview. Br J Healthcare Manag. 2016;22:488-92.

Keeler M, Haas BK, Northam S, Nieswiadomy M, McConnel C, Savoie L. Analysis of costs and ben- efits of transparent, gauze, or no dressing for a tunnelled central venous catheter in Canadian stem cell transplant recipients. Can Oncol Nurs J. 2015;25(3): 289-98.

Lorente L, Huidobro MS, Martín MM, Jiménez A, Mora ML. Accidental catheter removal in critically ill patients: a prospective and observational study. Crit Care. 2004;8:R229.

Loveday H, Wilson J, Pratt R, Golsorkhi M, Tingle A, Bak A, Browne J, Prieto J, Wilcox M. EPIC3: national evidence-based guidelines for preventing healthcareassociated infections in NHS Hospitals in England. J Hosp Infect. 2014;86:S1-70.

Macklin D, Blackburn P. Central venous catheter securement: using the Healthcare and Technology Synergy Model to take a close look. J Assoc Vasc Access. 2015;20:45-50.

Marsh N, Webster J, Flynn J, Mihala G, Hewer B, Fraser J, Rickard C. Securement methods for peripheral venous catheters to prevent failure: a randomized controlled pilot trial. J Vasc Access. 2015;16:237-44.

Mcnichol L, Lund C, Rosen T, Gray M. Medical adhesives and patient safety: state of the scienceconsensus statements for the assessment, prevention, and treatment of adhesive-related skin injuries. J Dermatol Nurs Assoc. 2013;5:323-38.

Moureau N, Poole S, Murdock M, Gray S, Semba C. Central venous catheters in home infusion care: outcomes analysis in 50,470 patients. J Vasc Interv Radiol. 2002;13:1009-16.

O'Grady N, Alexander M, Burns L, Dellinger E, Garland J, Heard S, Lipsett P, Masur H, Mermel L, Pearson M, Raad I, Randolph A, Rupp M, Saint S. Guidelines for the prevention of intravascular catheter-related infections. Center for Disease Control HICPAC Healthcare Infection Control Practices Advisory Committee: Guidelines for the prevention of intravascular catheterrelated infections. Atlanta: Center for Disease Control and Prevention; 2011.

Oliver G, Jones M. ECG or X-ray as the 'Gold Standard' for establishing PICC-tip location? $\mathrm{Br} \mathrm{J}$ Nurs. 2014;23(Suppl 19):S10-6. https://doi.org/10.12968/ bjon.2014.23.Sup19.S10.

PICC Excellence. Online course manuals. In: Moureau N, editor. www.piccexcellence.com. Accessed Mar 2018.

Pittiruti M, Scoppettuolo G, Emoli A, Musarò A, Biasucci D. Cyanoacrylate glue and central venous access device insertion. J Assoc Vasc Access. 2016;21(4):249.

Pittiruti M, Scoppettuolo G. Gavecelt Manual of PICC and Midline: Indications, insertion, management, Italy, Edna S.p.A.; 2017.

Pittiruti M, Hamilton H, Biffi R, Macfie J, Pertkiewicz M. ESPEN guidelines on parenteral nutrition: central venous catheters (access, care, diagnosis and therapy of complications). Clin Nutr. 2009;28:365-77.

RCN. Standards for infusion therapy. 4th ed. London: Royal College of Nursing; 2016. p. 1-94.

Regalado S, Funaki B. Novel devices for wound closure in interventional radiology. Semin Intervent Radiol. 2008;25(01):058-64. (C) Thieme Medical Publishers. 
Rickard CM, Marsh NM. Annals for hospitalists inpatient notes-the other catheter-the mighty peripheral IV. Ann Intern Med. 2017;167:HO2-3.

Rickard C, Mccann D, Munnings J, Mcgrail M. Routine resite of peripheral intravenous devices every 3 days did not reduce complications compared with clinically indicated resite: a randomised controlled trial. J BMC Med. 2010;8:53.

Rickard C, Webster J, Wallis M, Marsh N, Mcgrail M, French V, Foster L, Gallagher P, Gowardman J, Zhang L, Mcclymont A, Whitby M. Routine versus clinically indicated replacement of peripheral intravenous catheters: a randomised controlled equivalence trial. Lancet. 2012;380:1066-74.

Rickard CM, Marsh N, Webster J, Playford EG, Mcgrail MR, Larsen E, Keogh S, Mcmillan D, Whitty JA, Choudhury MA. Securing all intravenous devices effectively in hospitalised patients-the SAVE trial: study protocol for a multicentre randomised controlled trial. BMJ Open. 2015;5:e008689.

Rickard CM, Marsh N, Webster J, Runnegar N, Larsen E, Mcgrail MR, Fullerton F, Bettington E, Whitty JA, Choudhury MA. Dressings and securements for the prevention of peripheral intravenous catheter failure in adults (SAVE): a pragmatic, randomised controlled, superiority trial. Lancet. 2018;392(10145):419-30.

RNAO. Nursing Best Practice Guidelines: Assessment and Device Selection for Vascular Access. Nursing Best Practice Guidelines. Registered Nurses Association of Ontario; 2008.

Royer T. Improving short peripheral IV outcomes: a clinical trial of two securement methods. J Assoc Vasc Access. 2003;8:1-5.

Scoppettuolo G, Dolcetti L, Emoli A, La Greca A, Biasucci D, Pittiruti M. Further benefits of cyanoacrylate glue for central venous catheterisation. Anaesthesia. 2015;70:758.

Shivnan J, Mcguire D, Freedman S, Sharkazy E, Bosserman G, Larson E, Grouleff P. A comparison of transparent adherent and dry sterile gauze dressings for long-term central catheters in patients undergoing bone marrow transplant. Oncol Nurs Forum. 1991;18(8):1349-56.

Simcock L. No going back: advantages of ultrasoundguided upper arm PICC placement. J Assoc Vasc Access. 2008;13(4):191-7. https://doi.org/10.2309/java.13-4-6.
Simonova G, Rickard C, Dunster K, Smyth D, Mcmillan D, Fraser J. Cyanoacrylate tissue adhesives-effective securement technique for intravascular catheters: in vitro testing of safety and feasibility. Anaesth Intensive Care. 2012;40:460-6.

Smith B. Peripheral intravenous catheter dwell times: a comparison of securement methods for implementation of a 96-h scheduled change protocol. J Infus Nurs. 2006;29:14-7.

Thayer D. Skin damage associated with intravenous therapy: common problems and strategies for prevention. J Infus Nurs. 2012;35:390-401.

Ullman A, Cooke M, Mitchell M, Lin F, New K, Long D, Mihala G, Rickard C. Dressings and securement devices for central venous catheters (CVC). Cochrane Database Syst Rev. 2015a;(9):CD010367.

Ullman A, Cooke M, Rickard C. Examining the role of securement and dressing products to prevent central venous access device failure: a narrative review. J Assoc Vasc Access. 2015b;20:99-110.

Ventura R, O’Loughlin C, Vavrik B. Clinical evaluation of a securement device used on midline catheters. Br J Nurs. 2016;25:S16-22.

Webster J, Gillies D, O'Riordan E, Sherriff K, Rickard C. Gauze and tape and transparent polyurethane dressings for central venous catheters. Cochrane Database Syst Rev. 2011;(11):CD003827.

Wong W, Chan W, Ip S, Ng W, Chan C, Ho H, Siu K, Tan C. Infection rate of Hickman catheters versus peripherally inserted central venous catheters in oncology patients. Hong Kong J Radiol. 2015;18:197-204.

Yamamoto A, Solomon J, Soulen M, Tang J, Parkinson K, Lin R, Schears G. Sutureless securement device reduces complications of peripherally inserted central venous catheters. J Vasc Interv Radiol. 2002;13:77-81.

Yue J, Tabloski P, Dowal SL, Puelle MR, Nandan R, Inouye SK. NICE to HELP: operationalizing National Institute for Health and Clinical Excellence guidelines to improve clinical practice. J Am Geriatr Soc. 2014;62:754-61.

Zerla P, Canelli A, Cerne L, Caravella G, Gilardini A, De Luca G, Aricisteanu A, Venezia R. Evaluating safety, efficacy, and cost-effectiveness of PICC securement by subcutaneously anchored stabilization device. J Vasc Access. 2017;18(3):238-42.

Open Access This chapter is licensed under the terms of the Creative Commons Attribution 4.0 International License (http://creativecommons.org/licenses/by/4.0/), which permits use, sharing, adaptation, distribution and reproduction in any medium or format, as long as you give appropriate credit to the original author(s) and the source, provide a link to the Creative Commons license and indicate if changes were made.

The images or other third party material in this chapter are included in the chapter's Creative Commons license, unless indicated otherwise in a credit line to the material. If material is not included in the chapter's Creative Commons license and your intended use is not permitted by statutory regulation or exceeds the permitted use, you will need to obtain permission directly from the copyright holder. 